\title{
CHEMOTHERAPY
}

a public health measure

\section{AGAINST TUBERCULOSIS}

\author{
EDWARD T. BLOMQUIST, M.D.
}

Some considerations on how to act upon the major recommendation of the Arden House Conference on Tuberculosis.

$\mathrm{T}$ HE present status and future of tuberculosis control in this country was considered at the Arden House Conference on Tuberculosis held November 29-December 2, 1959. All of us closely involved felt at the time that it was an important conference, and the attention and consideration it has attracted offer proof that we were right. Many ideas and proposals have resulted from this conference, and there has been time for them to be examined critically. The ones that have survived are not revolutionary; they are practical, however, and this means a good deal.

The following thoughts have grown from many conversations, discussions, and even arguments on how the major recommendation of the Arden House Conference can be translated into action. I felt obligated to summarize my ideas this way since time is important. It seems to me imperative that suggestions on practical steps for carrying out the Arden House recommendations be advanced quickly, and to all interested in this field. If all of us concerned with tuberculosis in this country do not act quickly, a real opportunity will be lost. We must make the Arden House Conference produce something more than words and

Dr. Blomquist is chief, Tuberculosis Branch, Division of Special Health Services, Public Health Service. justify the interest and enthusiasm it has engendered.

\section{The Present Situation}

Since chemotherapy came into use, the death rate from tuberculosis has gone down sharply. Although the case rate has also been moving downward, it has apparently been affected less by the new drugs. The relatively slow decline of case rates can be accounted for in part by the large proportion of tuberculosis cases in the United States that result from the breakdown of old infections. At the present time no measure is available to prevent most of these, but more adequate treatment of all cases that do occur could prevent the cases that arise from recent exposure. In addition, it could prevent the new infections in those who would become the tuberculosis patients of the future or subjects for prophylactic treatment, if that becomes a reasonable measure. This, I believe, was the rationale back of the major recommendation made at Arden House.

Of course, to a great extent it is a reiteration of long-accepted principles. Casefinding, diagnosis, and treatment have been the basis of tuberculosis control for many years. But when treatment was a long, drawn-out course requiring months or years of bed rest, it was necessarily to a large extent the separate responsibility of 
the hospital. When patients could not get into a hospital, most health departments made an attempt to effect some kind of isolation in the home and to provide such outpatient treatment as there was, but this was always regarded as less than satisfactory. Ideally, the patient entered the hospital and stayed there until he had fully recovered.

Under optimum conditions, chemotherapy can reverse the infectiousness of most tuberculosis patients within 3 to 5 months, and of many, much sooner. Most patients under chemotherapy do just as well whether they are ambulant or on bed rest. Obviously, therefore, the majority of patients need not be in a hospital for the entire course of their treatment. Indeed, some patients can be satisfactorily treated without ever going to one.

As a result of these new wonders, the average term of hospital care has become shorter, and many tuberculosis hospitals have closed or converted to other purposes. The quite reasonable assumption is that tuberculosis patients now can be more economically treated in the community. The trouble is that while outpatient treatment can be adequate, it often is not. Health departments have not been staffed or equipped to take care of large numbers of tuberculosis patients. The declining death rate and the closing of hospitals have been interpreted by the public as evidence that tuberculosis services in general can be cut back, and health departments are in considerable difficulty keeping what they have. New treatment services, either in the health department or in other community facilities, are rarely considered. Tuberculosis specialists are in short supply. Few young physicians now choose this specialty, and as tuberculosis hospitals close, members of their medical staffs retire or go into other fields of medicine.

In a great many communities, therefore, most tuberculosis patients are getting inadequate treatment or none at all. They remain as much of a potential problem in public health as were the patients on hospital waiting lists in prechemotherapy days.

\section{A Different Approach in Confrol}

The solution, it appears to me, lies in changing the order of our thinking about tuberculosis control-in being realistic in terms of the tools

\section{Arden House Conference Recommendation}

The major recommendation of the conference is a program for the widespread application of chemotherapy as a public health measure for the elimination of tuberculosis in the United States.

Goal. To sterilize that important part of the reservoir of tubercle bacilli that presently exists throughout the country in persons currently suffering from active tuberculous disease, whether presently known or unknown to public health authorities, and in selected persons who previously have had active disease and were inadequately treated.

Technique. Mobilize all resources for a widespread application of the scientifically demonstrated and medically accepted procedures of adequate chemotherapy. These include the proper dosage of appropriate drugs or combination of drugs given continuously over an adequate period of time-procedures that are known to destroy tubercle bacilli in the human body, render the patient's disease noncommunicable to others, and minimize the possibility of reactivation.

we now have to work against the disease. Where we used to say, "We must find all the persons with tuberculosis, and then treat as many as we can-at least then we will know who they are," I believe the Arden House recommendation is asking us to say, "We will treat all the persons with tuberculosis, and of course, since we do not know who some of them are, we must find them in order to treat them." If we place treatment at the center of our thinking, it can be a much more effective public health measure than it has been so far.

I should like to warn against equating "public health" with "health department." In our complex social organization, a great many agencies and individuals, both public and private, are engaged in activities concerned with public health. Poliomyelitis or DTP injections protect the public health whether they are given in the health department or the private physician's office. In some places, the health department provides treatment for tuberculosis patients in clinics or hospitals or both; in others, the health department does not give any kind of medical care, but treatment is still a public health meas- 
ure. Casefinding for tuberculosis is public health activity, whether it is done by the health department or the tuberculosis association. To be sure, the health department has legal responsibility for tuberculosis control, but that does not mean it carries on all tuberculosis control activities in the community. Before any significant change in emphasis in this area can come about, there must be a change in the thinking and activities of many other agencies and individuals as well.

\section{Stages of Control}

If we accept this interpretation of the major conference recommendation, what then can be done to carry it out? Certainly there will be wide variation in different areas, depending greatly upon the adequacy of present tuberculosis control programs, but the following general suggestions seem reasonable. For convenience, we can divide tuberculosis control as far as treatment is concerned into three stages: Stage 1, in which the community is not now able to provide adequate treatment for presently known active cases; stage 2, in which the program proposed for stage 1 is well underway; stage 3 , in which programs for both previous stages are adequate.

Stage 1. In a community where any significant proportion of the patients with known active cases of tuberculosis are not receiving adequate treatment either in the hospital or at home, the first efforts should be to remedy that situation, by whatever means and using whatever resources the community has. Treatment would include the prophylactic administration of isoniazid to those groups of young children for whom its usefulness has been demonstrated. Casefinding should be deferred except for careful followup of all close contacts of persons known to have active disease and complete diagnosis of suspects among them.

Stage 2. If a high proportion, perhaps 75-80 percent, of persons known to have active disease are under treatment, and most contacts are being examined, casefinding should be extended, as resources are available, beyond the contact group to other high-incidence groups, but this should be done without taking staff time needed for treatment programs for active cases. The community is now in a posi- tion to add to its treatment program the persons who have previously had active disease but are judged to have been inadequately treated. Prophylactic treatment for persons known to have recently converted from tuberculin negative to positive is also in order.

Stage 3. The community that has reached stage 3 presumably has found most of its active cases, and they are under adequate treatment. In addition, certain categories of inactive cases have been found and are being treated. It can then undertake to find and treat persons at especially high risk, such as tuberculin reactors with suspicious $14^{\prime \prime}$ by $17^{\prime \prime}$ chest X-rays or silicotics with large tuberculin reactions or X-ray changes, or both.

This proposal to consider tuberculosis control in three stages implies knowledge of the current status of tuberculosis cases. Details about what information should be gathered, and how records should be kept and data analyzed in order to have such knowledge, are not appropriate here, but the subject is of very great importance. Similarly, approaches to casefinding, although they will not be discussed here, will require careful judgment and planning.

Many communities in the United States, in spite of our generally favorable situation, are still at stage 1. That is, a considerable proportion of the known active cases in the community are not receiving adequate treatment. Concentrating control efforts on treatment may help in some instances, but in order to progress to more favorable stages, these communities will have to find ways of increasing treatment resources. Ideally, of course, tuberculosis treatment services include hospital care and outpatient care, coordinated in such a way that patients who need to be in the hospital can be, and patients who do not need hospital care can be taken care of outside of the hospital. Since such coordination is so often not the actual practice, I will discuss hospital care and outpatient care separately.

\section{Outpatient Care}

The need to improve the quality of treatment received by tuberculosis patients outside the hospital is an insistent issue. Most big cities do provide adequate to excellent outpatient 
treatment; because they usually have large caseloads, they may need more services and facilities, but the quality of their treatment programs is by and large very good. In many smaller communities, however, tuberculosis patients who are not in a hospital receive meager treatment or none at all. Little can be done to "mobilize all resources for a widespread application of the scientifically demonstrated and medically accepted procedures of adequate chemotherapy" in such situations without some new thinking and a willingness to explore every possibility.

Although new funds or additional professional workers are not easy to obtain for tuberculosis programs at present, the possibility of getting either will be much better if the best use is made of money and people now available and if specific proposals can be made for the use of new money. I have therefore been considering what is needed for good tuberculosis outpatient chemotherapy treatment and attempting to spell out a number of possible ways of providing what is needed. While the suggestions made are directed especially toward services for the 50 percent of patients who live elsewhere than in cities of more than 100,000 population, some of them may apply in urban centers as well.

The various services needed for a treatment program may be provided by different agencies or paid for from different funds, but the success of each in promoting the recovery of tuberculosis patients depends upon how well they all supplement and support each other. In most communities, the health department, because of its legal responsibility for tuberculosis control, is the most appropriate agency to coordinate all services for tuberculosis patients.

In the big cities the number of tuberculosis patients treated in outpatient facilities is suffciently large to require full-time medical staff for tuberculosis clinics. Elsewhere, the limited time of consultant physicians is used for film reading or evaluation of patients' records, and it is common for tuberculosis patients to see a physician only very rarely. When the patient comes to the clinic, he sees a nurse, who has the responsibility of interpreting to him whatever information or recommendations the physician may have recorded when he reviewed the case.
She must answer the patient's questions and encourage him to continue treatment. Her record of her interview with the patient is all the physician has to go by except laboratory reports and $\mathrm{X}$-rays. In this kind of situation, the nurse carries an inappropriate burden. The physician cannot give the professional services the patient needs, and the patient is often unsatisfied and disinclined to follow recommendations that reach him secondhand. For the patient with tuberculosis, certainly when it is active, seeing a physician once a month seems a reasonable requirement.

Remedies are not easily at hand, but a number of possibilities are worth consideration. The limited time of the tuberculosis specialist, who perhaps comes into the community only occasionally, might be better used in consultation with local general practitioners, who in turn could provide continuing medical care to patients. In this kind of arrangement, when patients were unable to pay, the local physicians could be paid for their services by the health department, the tuberculosis hospital board, or whatever agency is responsible for care of tuberculosis patients. The advice of the county medical society could be sought in selecting physicians, and in arranging for them to be paid. It would seem wise, moreover, for specialist consultation to be available to all physicians treating tuberculosis patients, whether the patient or the community pays for the treatment.

Another plan that has been found feasible in some areas is the staffing of tuberculosis outpatient clinics by physicians from tuberculosis hospitals. If clinics are held in communities within a reasonable distance from the hospital, it should be possible for them to be frequent enough to allow physicians to give patients appropriate personal attention.

In communities where the tuberculosis clinic caseload is not large enough to justify full-time medical staff but where there is a chest physician, or an internist or general practitioner with special interest and training in chest diseases, an arrangement might be made for part-time service from the private physician, for which he would be paid by the appropriate agency. A high proportion of tuberculosis patients now are not able to pay for long-term 
medical care, and the number of those who can is in many areas not large enough to support a private practice. Fees paid for clinic work would in some instances make it possible for a physician to afford to specialize.

If physicians are to give proper treatment to tuberculosis patients, laboratory and $\mathrm{X}$-ray services must be readily available. In the ideal situation, the physician has the laboratory report and X-ray, when he has ordered these, at the time he sees the patient. Too often the $X$ ray the physician sees is one taken at the time of the last visit, which may have been too long a time before to give a picture of the present condition. It may be necessary to have facilities that make it possible to develop and dry $\mathrm{X}$-rays quickly, so that they can be taken on the day of the appointment, or to make special arrangements for patients to come in for $\mathrm{X}$ rays a few days before their clinic appointments.

Laboratory work should include not only smears and cultures for Mycobacterium tuberculosis, but also drug sensitivity tests and, especially in some areas, tests for atypical organisms. If the health department does not have a laboratory, a local hospital laboratory may be able to do the work. Tuberculosis associations are a possible source of help in paying laboratory salaries or financing the training of laboratory staffs.

That a chemotherapy program cannot succeed without readily available drugs is a truism. Many programs, however, do not have a budget for this purpose. The cost of tuberculosis drugs is relatively low, but even a small amount of money may be beyond the means of a patient who is subsisting on a welfare budget. Or it may be the reason for lack of cooperation in one who is not very enthusiastic about following medical recommendations. If the health department or hospital board, or whatever agency is providing medical care, does not have funds for this purpose, they can perhaps get help from the tuberculosis association or other agencies in the community. The administration of funds for drugs belongs in the clinic, so that drugs can be readily given to patients. without individual and separate arrangements.

The public health supervision of patients with active disease is of course the responsibility of the health department and is done chiefly by public health nurses. If seriously ill patients are hospitalized and medical supervision of clinic patients is adequate, the nursing service needed for an outpatient tuberculosis treatment program can be given in most communities by the health department's generalized nursing service. When medical supervision is inadequate, however, patients may be carried as "active" or "activity undetermined" cases for long periods without evaluation. Thus the nursing caseload of tuberculosis patients becomes unreasonably large, and priorities for service difficult to establish. Patients may be neglected in the first few days after diagnosis when help given to them and their families in understanding their illness and learning what to do about it could have long-term benefits.

The public health nurse contributes so greatly to tuberculosis control that she often has pushed upon her tasks it is unreasonable to expect her to do. The sometimes laborious and time-consuming job of trying to locate a patient who has moved or cannot be found can be done by someone other than a nurse. This might be a part-time job for a trained layman, or a full-time job shared by several communities. Assignment of trained laymen for this purpose has been worked out successfully by at least one State.

In some areas, public health nurses give twice-weekly streptomycin injections, and this is another task that could well be done by someone else. If there is no visiting nurse service, a registered or practical nurse could be hired specifically for this purpose. Married nurses might be found who could take it as part-time work.

In all of these instances, if public funds are not available, tuberculosis association help might be sought to pay salaries.

Chemotherapy applied as a public health measure requires a system of providing services in a way that does not place the patient on one side and the community on the other. The patient's ability and willingness to accept treatment are as important as the services offered. While it cannot be denied that a small percentage of tuberculosis patients will remain stub- 
bornly uncooperative in spite of every effort, most patients will stay with recommended treatment if it is possible and reasonable for them to do so.

The location of clinics is an important factor in such a system. While modern transportation allows one clinic to serve a fairly large area, it is not reasonable to expect patients to make a half day's journey to the clinic. Volunteers can serve effectively in taking patients to and from the clinic. If they cannot be recruited, and patients must use public transportation, some arrangement must be made to pay their fares.

- Scheduled appointments and reminder letters should be a part of the system, and if volunteers can be found to interest themselves in getting patients to the clinic, they may be helpful in the reminding. The clinic itself should be made as pleasant and attractive as possible, and here again volunteers can often be helpful. A coat of paint may not transform dingy quarters completely, but it can help a great deal in making them more cheerful.

The area of economic and social assistance is too broad to discuss in detail, but a patient cannot be expected to stop work in order to protect the community from his infection unless the community takes some responsibility for income sufficient for food, shelter, and other necessities of life for him and his family.

The public health purpose of tuberculosis treatment also precludes withholding drugs or services from patients because they have left the hospital against advice or committed minor infractions of rules. It indicates instead a conscious attempt to work out with the patient a regimen that he can accept, even if it would not be the first choice of the physician. The patient's cooperation is so essential that all reasonable concessions are justified in order to obtain it.

\section{Hospital Care}

Hospital care is the most costly single item in tuberculosis control. Even though a great many tuberculosis hospitals have closed or have been converted to other uses, rising unit costs have kept the total cost high. The most advantageous use of hospitals in the total program of tuberculosis treatment is therefore of utmost importance.
I think there is little disagreement with the concept that a period of hospitalization, beginning as soon as a diagnosis is established, provides the best circumstance for recovery for any tuberculosis patient. How long the patient should stay in the hospital is a matter about which there is a greater range of opinion. The most conservative position is that the patient should stay until he has fully recovered. While chemotherapy has made this a shorter period than used to be necessary, "full recovery" even today means about 18 months. The trend in many hospitals is toward much shorter stays, until the disease is inactive (about 9 months in the majority of cases), or, even less conservative, until the patient is no longer infectious (not more than 6 months in the majority of cases).

Two issues in addition to the theoretical "best circumstance" for treatment of tuberculosis need to be considered in recommended length of hospital stay. In both, it is implicit that in order to provide good care for tuberculosis patients the hospital must operate as a part of the community. The two issues are: first, whether the patient will continue to receive adequate care when he leaves the hospital; and second, whether he is willing to stay in the hospital or, in his own thinking, is able to do so.

Because of the first issue, it is not unusual for hospitals to keep patients, or to try to, for longer periods than now are actually necessary. Hospitals may be separated from community clinic services, either because they fall in different government jurisdictions or because they are geographically isolated, or both. In some communities, as I have already said, appropriate clinic services do not exist. For all of these reasons, it is not surprising that hospital staffs sometimes feel they are giving the patient the best chance of recovery if they keep him for the full course of his treatment. Looking at the matter objectively, and in terms of what is best for tuberculosis control, however, it seems apparent that a better course would be for the hospital to take a hand in providing clinic services, either in its own outpatient department or elsewhere, if its location makes that impractical. If the hospital is under one government department and an existing clinic in need of staff under another, negotiation may be necessary, but 
such a situation is not an insurmountable obstacle.

An orderly plan for chemotherapy as a public health measure includes hospitalization for patients who need it when they need it, and therefore requires the wisest use of expensive hospital facilities-for newly diagnosed patients and for patients who need surgery or who do not respond to therapy. (Some patients remain infectious in spite of the best possible treatment, but it seems reasonable that such "lifetime" patients can be cared for with less than a full range of hospital services.) Physicians treating patients in clinics should be able to get them hospitalized when it is suitable. Clinging to the old patterns of prolonged stay for all patients admitted and separation of hospital and clinic does not fit into such an orderly plan.

The second issue, how the patient feels about hospitalization, is also a concern in public health. The AMA rates in many hospitals are very high. Even if one were to take the attitude that all those who left against advice should be rounded up and returned to a locked ward, it would be impossible to carry out that kind of policy. If, on the other hand, an attempt is made to accommodate recommendations somewhat to the patient's feelings about going to the hospital, it seems likely that more patients can be helped to get more benefit from hospital care. The patient who is dismayed at the prospect of months in the hospital can perhaps be persuaded to stay for 1 month. If that month is recognized as a planned short stay, and used as an opportunity for intensive care and education, it may prove more profitable in the long run than several months that end when the patient gets fed up and leaves.

A plan like this would of course require good prospects for outpatient care after hospitalization, and here again the hospital would have to have a part in the responsibility to see that it was provided. If the hospital is to continue as the principal purveyor of medical care for tuberculosis patients, it can no longer reasonably concern itself only with those patients who willingly stay for the recommended period.

I do not deny that some small percentage of patients, like a small percentage of the total population, are genuinely recalcitrant and will not cooperate with any recommended course.
For these, forcible isolation is probably the only solution. But many others would accept and follow through with outpatient treatment that was planned with them. And treatment that is less than ideal is better if it is completed than the best possible treatment if it is abandoned.

At the Arden House conference, one of the participants commented on the problem that arises because so many tuberculosis patients are in lower socioeconomic classes, while public health and medical professional people are chiefly from the middle class. He pointed out that the professional person often tries to impose his own ideals and aspirations upon the patient and is frustrated to get no response. Many of us, for instance, knowing the overcrowded, dilapidated, depressing (to us) homes some patients come from, feel that they ought to be happy to be in the nice clean hospital. We think they are ornery if they prefer to stay at home. It takes imagination, and a willingness to accept when we cannot imagine, to help patients toward a way to recovery, but success in using chemotherapy as a public health tool depends upon it.

\section{State Planning}

Patterns for providing treatment services for tuberculosis patients vary widely in the States. In a small group of States, none of the public tuberculosis hospitals is supported solely by the State, and in a few they all are. The most common pattern, however, is a combination of State hospitals and county or city hospitals. Whether they are State or local, hospitals may be under the health department, a separate hospital department, or under the welfare department. Clinic services come under equally varied auspices.

While efficient and effective treatment services are possible under many different organizational plans, the present situation in tuberculosis does call for coordination at the State level, in order to make sure that patients are treated no matter whether they live in low or high incidence areas, and also for the sake of economical operation. It seems important now to plan services according to reasonable caseloads. Obviously it is wasteful for several counties in a State to run tuberculosis hospitals in which 
many beds are unoccupied. Under a State plan, such counties can be encouraged to pool their resources, thereby saving both money and staff which can perhaps be diverted to outpatient services. In some areas of the United States, tuberculosis patients outside the hospital are too few to justify a monthly clinic in a single county. Even if county health departments can arrange for local physicians to give medical care, the State may need to see that laboratory services, perhaps $\mathbf{X}$-ray facilities or interpretation or consultation, are provided. If local medical care is not available, the State may have to arrange for physicians to be brought in once a month to see patients.
The amount of direct service or financial assistance the State gives is not at issue. Any State health department should be able to serve in a coordinating capacity.

In a number of States, well-established precedents for intercounty cooperation enable the State health department to work out a State plan for tuberculosis treatment as easily as in States with completely centralized services. Where local autonomy is highly prized, however, a good deal of persuasion and convincing may be necessary. In this case, interpreting the advantages of banding together may have to be the job of citizens' groups such as the State tuberculosis association.

\section{Illegitimacy Report}

A report on illegitimacy and its relation to aid to dependent children (ADC) has been published in booklet form by the Bureau of Public Assistance, Social Security Administration. The material was prepared at the direction of the Senate Appropriations Committee on the 1960 appropriation bill for the Labor and Health, Education, and Welfare Departments.

In transmitting the study, the Commissioner of Social Security, William L. Mitchell, pointed out that "the great majority (over two-thirds) of the children under 18 who were born out of wedlock are living with natural parents or relatives. Only one out of eight is receiving support through the aid to dependent children program." The study reveals that:

- Over a 20-year period the increase in illegitimate births has been from about 4 to about 5 in each 100 live births.

- Children of unmarried mothers represent 16 percent of all ADC children, and their families account for 20 percent of all ADC families. The proportion has risen not only because of the rise in the number of illegitimate children but also because the oldage, survivors, and disability insurance program has increasingly provided income for children whose fathers have died, with the result that few children whose fathers are deceased receive ADC benefits.
- Almost half of all aid to dependent children families have incomes, including their assistance payments, below the subsistence level measured by the States' assistance standards.

- The average time that $A D C$ is received for children of unmarried mothers is less than $2 \frac{1}{2}$ years. The great majority of illegitimate children on ADC were born before the family received assistance.

- Many ADC families are partially self-supporting: almost half have income in addition to assistance, principally from earnings of the mothers and contributions from the fathers.

- More than 15 percent of the mothers of illegitimate children work full or part time.

The report states that "it would be surprising if the motivating factor in repeated pregnancies out of wedlock were the mother's desire to increase her assistance payment to cover part of the basic cost of rearing another child."

Entitled "Illegitimacy and Its Impact on the Aid to Dependent Children Program," the report used, in large part, material from many State and local agencies and private organizations. The National Office of Vital Statistics, the Public Health Service, and other government and voluntary agencies also analyzed and prepared special materials. 